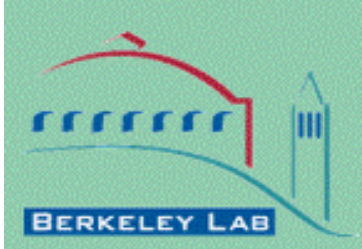

\section{ERNEST ORLANDO LAWRENCE \\ BERKELEY NATIONAL LABORATORY}

\author{
Aimee McKane*, Ivyn Rhyne**, Alex Lekov*, \\ Lisa Thompson*, Mary Ann Piette* \\ *Lawrence Berkeley National Laboratory, \\ **California Energy Commission,
}

August 2009

This manuscript has been authored by an author at Lawrence Berkeley National Laboratory under Contract No. DE-AC02-05CH11231 with the U.S.Department of Energy. The U.S. Government retains, and the publisher, by accepting the article for publication, acknowledges, that the U.S. Government retains a non-exclusive, paid-up, irrevocable, world-wide license to publish or reproduce the published form of this manuscript, or allow others to do so, for U.S. Government purposes. 



\section{Disclaimer}

This document was prepared as an account of work sponsored by the United States Government. While this document is believed to contain correct information, neither the United States Government nor any agency thereof, nor The Regents of the University of California, nor any of their employees, makes any warranty, express or implied, or assumes any legal responsibility for the accuracy, completeness, or usefulness of any information, apparatus, product, or process disclosed, or represents that its use would not infringe privately owned rights. Reference herein to any specific commercial product, process, or service by its trade name, trademark, manufacturer, or otherwise, does not necessarily constitute or imply its endorsement, recommendation, or favoring by the United States Government or any agency thereof, or The Regents of the University of California. The views and opinions of authors expressed herein do not necessarily state or reflect those of the United States Government or any agency thereof, or The Regents of the University of California.

Ernest Orlando Lawrence Berkeley National Laboratory is an equal opportunity employer. 



\title{
Automated Demand Response: The Missing Link in the Electricity Value Chain
}

\author{
Aimee McKane, Lawrence Berkeley National Laboratory \\ Ivin Rhyne, California Energy Commission \\ Alex Lekov, Lawrence Berkeley National Laboratory \\ Lisa Thompson, Lawrence Berkeley National Laboratory \\ Mary Ann Piette, Lawrence Berkeley National Laboratory
}

\begin{abstract}
In 2006, the Public Interest Energy Research Program (PIER) Demand Response Research Center (DRRC) at Lawrence Berkeley National Laboratory initiated research into Automated Demand Response (OpenADR) applications in California industry. The goal is to improve electric grid reliability and lower electricity use during periods of peak demand.

The purpose of this research is to begin to define the relationship among a portfolio of actions that industrial facilities can undertake relative to their electricity use. This "electricity value chain" defines energy management and demand response (DR) at six levels of service, distinguished by the magnitude, type, and rapidity of response. One element in the electricity supply chain is OpenADR, an open-standards based communications system to send signals to customers to allow them to manage their electric demand in response to supply conditions, such as prices or reliability, through a set of standard, open communications.

Initial DRRC research suggests that industrial facilities that have undertaken energy efficiency measures are probably more, not less, likely to initiate other actions within this value chain such as daily load management and demand response. Moreover, OpenADR appears to afford some facilities the opportunity to develop the supporting control structure and to "demo" potential reductions in energy use that can later be applied to either more effective load management or a permanent reduction in use via energy efficiency. Under the right conditions, some types of industrial facilities can shift or shed loads, without any, or minimal disruption to operations, to protect their energy supply reliability and to take advantage of financial incentives. ${ }^{1}$

In 2007 and 2008, 35 industrial facilities agreed to implement OpenADR, representing a total capacity of nearly $40 \mathrm{MW}$. This paper describes how integrated or centralized demand management and system-level network controls are linked to OpenADR systems. Case studies of refrigerated warehouses and wastewater treatment facilities are used to illustrate OpenADR load reduction potential. Typical shed and shift strategies include: turning off or operating compressors, aerator blowers and pumps at reduced capacity, increasing temperature set-points or pre-cooling cold storage areas and over-oxygenating stored wastewater prior to a DR event.

This study concludes that understanding industrial end-use processes and control capabilities is a key to support reduced service during DR events and these capabilities, if DR enabled, hold significant promise in reducing the electricity demand of the industrial sector during utility peak periods.
\end{abstract}




\section{Introduction}

The industrial facility of the future will have the capability to extract the maximum physical and monetary value from the energy used on their premises. In addition, these facilities will possess sufficient real time energy information and control capability to decide when and how much energy to use or store for later use, based on its price, source, and other factors valued by facility managers. For some facilities, onsite energy production will allow them to become net suppliers to the grid during peak periods.

Purchase, production, and use of energy in an industrial facility based on real time information can be described as "active energy management". Realizing this scenario depends on 1) technical factors (e.g. controls and data management software), 2) financial factors (e.g. energy tariff structures and production considerations), and 3) regulatory conditions (e.g., restrictions and/or fees for selling power to the electricity grid). While recognizing the importance of regulations in creating favorable conditions or obstacles, this paper will focus on technical and financial factors.

Technical advances such as the emergence of cost-effective and robust wireless sensors, high quality system level network controls, and asset management software leading to fully integrated "dash boards" will afford many managers their first meaningful access to real-time data on facility operations, previously limited to large energy-intensive and/or high risk manufacturing processes. Increases in the cost of delivered energy, concerns about adequacy of supply, and decoupling of energy markets have created financial conditions more favorable to both energy efficiency and demand response.

\section{The Electricity Value Chain}

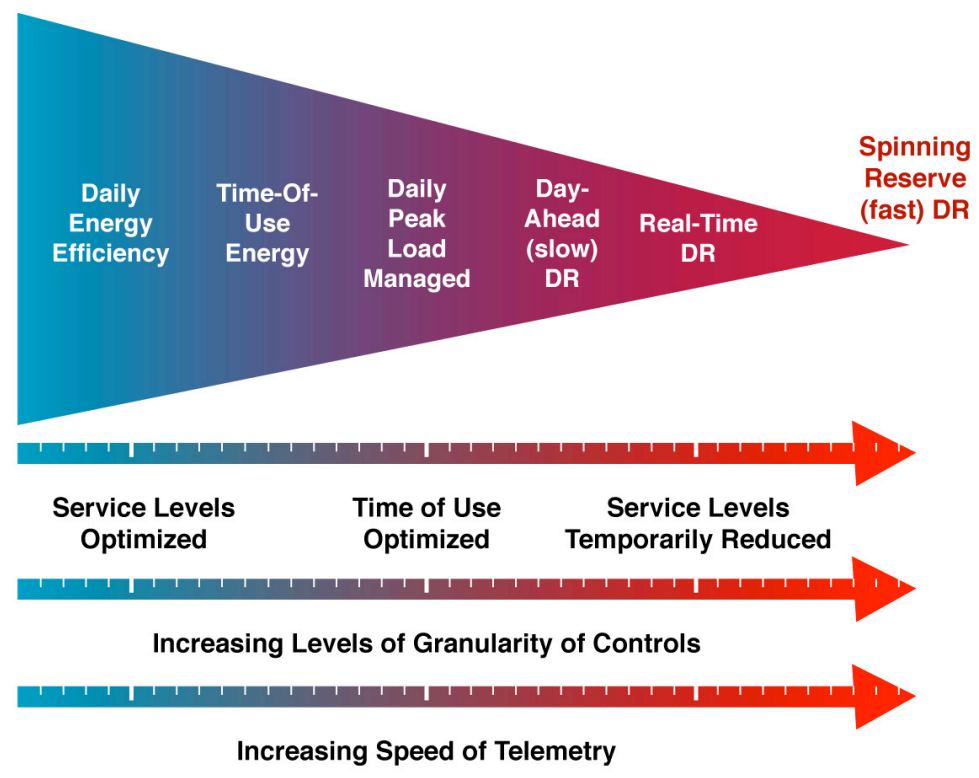

Figure 1: Electricity Value Chain ${ }^{2}$

This paper presents the concept of the "electricity value chain', as illustrated in Figure 1, which encompasses a portfolio of actions that industrial facilities can undertake relative to their 
electricity use, defining energy management and demand response at six levels of service, distinguished by the magnitude, type, and rapidity of response. Figure 1 also provides a framework for considering measurements of electricity use and services provided by electricity. For demand response events (right region of Figure 1), both the timing and quantity of electricity are important considerations. DR events are best managed when accurate and timely information is available about production and service level changes. The arrow below the service level description indicates that the ability to perform DR is enhanced with greater granularity of controls. An example is the use of electric load reductions using variable frequency drives rather than on-off control. The bottom arrow on telemetry indicates that remote signals for DR have varying requirements. Day-ahead information is less demanding than the speed required for dayof DR or telemetry for fast ancillary services.

\section{What is OpenADR?}

OpenADR is an open, secure communications data model to disseminate signals to customers to allow them to manage their electric demand in response to supply conditions, such as prices or reliability, through a set of standard, open communications. With suitable capabilities, facility control systems can carry out load reduction strategies using customized, preprogrammed DR strategies that can be activated upon receiving DR event or price signals.

OpenADR is designed to provide dispatchable operational DR capability similar to conventional generation resources. Open ADR provides an online portal for participating companies to opt-out from the DR event, should that become necessary. For more information about the Open ADR standard and its applicability to Smart Grid, see httn://www.nist. gov/smartorid/standards.html

\section{The Economics of the Electricity Value Chain}

\section{Research Hypothesis:}

Industrial facilities that have undertaken energy efficiency measures are more, not less, likely to initiate other actions such as load management and demand response (both manual and automated).

Investigating this hypothesis requires an understanding of the economic underpinnings of both efficiency and demand response activities.

Electricity is an input to production much like materials or labor. It is imperative that firms balance the needs of production and revenue generation with the costs associated with each input. This classical optimization problem has been studied extensively and is a central part of operations, engineering, and management programs. From this perspective, the problem facing a firm can be framed in economic terms. Any reduction in input costs reduces the cost of production and therefore can be viewed as a revenue source. Any increase in operating costs or reduction in quality or quantity of output is a source of costs.

Taking costs and revenues together, the goal of the industrial electricity user is to maximize total profit generated by the electricity value chain. This is accomplished by balancing the use and savings of electricity in the production process. Profit maximization occurs where the marginal cost of saving a kilowatt-hour (kWh) of electricity just equals the marginal revenue generated by the savings. 


\section{Marginal Revenue}

The marginal revenue generated by saving a $\mathrm{kWh}$ of electricity is determined by the underlying cost of purchasing that $\mathrm{kWh}$. Half a century ago, electricity was so cheap and plentiful that customers faced rate structures that encouraged the purchase of electricity in bulk with "inverted" tier rates where the price would decline steadily as the customer purchased more. Today electricity is a scarce commodity where the wholesale market shows wide swings in the price of electricity depending on the time of year and even time of day it is purchased.

The actual tariff structure faced by a firm determines the shape of the marginal revenue curve. For the purposes of this analysis we will limit ourselves to three rate structures; standard tiered, Critical Peak Price with underlying Time Of Use (CPP/TOU), and real time pricing (RTP). Figures $2 \mathrm{a}$ and $2 \mathrm{~b}$ illustrate the potential shapes of the marginal revenue curve under these three possible rate structures.

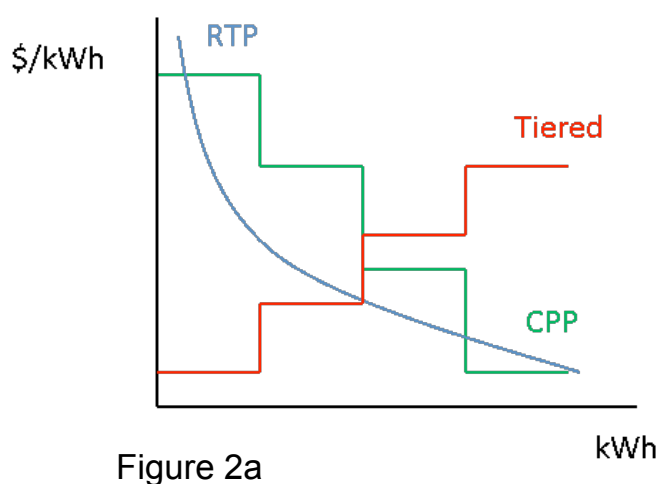

Figure 2a

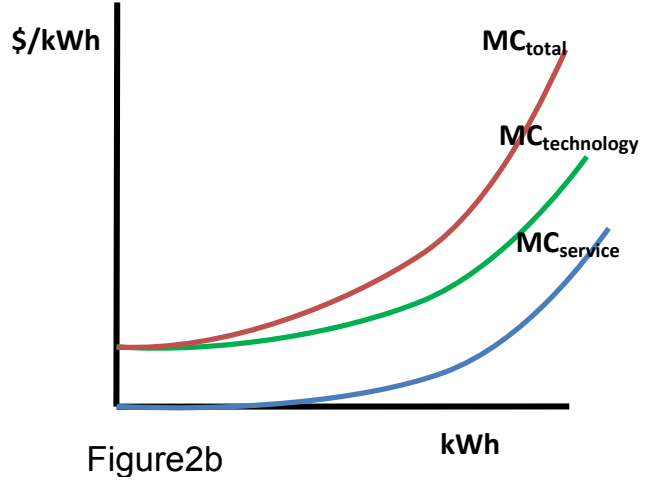

Figure2b

Figures 2a and 2b: Marginal Revenue and Components of Costs

Figure 2a (Marginal Revenue) is illustrative of the paradox of energy savings under standard tiered rate structures. The highest marginal revenue is not generated until the lower revenue savings are exhausted. As will be seen later, when combined with the marginal cost curves associated with saving energy, this creates a potential disincentive to save energy, especially among the more profit-focused commercial and industrial sectors. In contrast to the standard tiered rate approach, the CPP/TOU and RTP pricing structures do not prevent firms from attempting to target the highest value $\mathrm{kWh}$ first, leaving lower value $\mathrm{kWh}$ for later. Figure 2 is constructed on the principle that the highest value $\mathrm{kWh}$ are likely to be addressed first by any firm, regardless of the specific strategy employed.

\section{Marginal Cost}

The marginal cost curves associated with energy saving strategies can be decomposed into two distinct components. The first is the marginal cost of technology. This is the additional cost necessary to invest in technology in order to extract one more $\mathrm{kWh}$ of electricity savings. Unlike most equipment or capital intensive optimization problems, the marginal cost of electricity-saving equipment increases as the target $\mathrm{kWh}$ increases. For a given level of investment, the technology is assumed to be used to its 
energy-saving potential. This principle suggests that the marginal cost of investing in energy-saving equipment will eventually rise.

The second component of the marginal cost curve is the cost of reduced levels of service. This cost begins very small and grows quickly as the number of $\mathrm{kWh}$ saved increases. This is because the "level of service" produced by any industrial or commercial process is the output of the process. Modern commercial and industrial firms can have literally hundreds of different processes, each of which has various impacts on the firm's ability to deliver their saleable good or service. For example a food processing facility will have process that deal with the handling, cooking, and packaging of the food, processes to handle the waste material like food scraps and water, and processes that provide light and comfort for workers.

Under past paradigms, it didn't matter how much electricity was used to accomplish any of these processes because it was so cheap. Under the "electricity value chain" paradigm, managers must deal with the high price, and therefore high value, of the electricity used to accomplish each of these processes. From the point of view of the operations manager each of these processes have two important characteristics; quantity of service and quality of service.

- Quantity of Service: This term refers to the raw amount of output of a commercial or industrial process in order to support the delivery of a saleable good or service. This can be measured in any relevant term - minimum number of lumens for lighting systems, gallons per day for wastewater systems, or cases of goods handled or pounds of materials produced for production systems.

- Quality of Service: This term refers to the minimum level of quality or limiting quality constraint of a commercial or industrial process. For example a wastewater treatment plant must discharge below a set level of dissolved oxygen to meet regulatory requirements.

The use of electricity to accomplish both the necessary quantity and quality of service gives rise to the shape of the marginal cost curve depicted in Figure 2b. Initially the cost to the company in terms of both quantity and quality are very small. As larger and larger reductions in $\mathrm{kWh}$ savings are sought, more and more disruptions to the levels of service must be accommodated. This means that while the marginal cost of technology is rising as $\mathrm{kWh}$ savings increases, the marginal cost of service is also rising. 


\section{Demand Response and Energy Efficiency Strategies}

The final piece to the puzzle is to reexamine the question of whether energy efficiency and demand response are mutually exclusive strategies. Energy efficiency and demand response occupy two different ends of the energy savings spectrum. The practical difference between these strategies however is not as large as it may appear. Their primary differences are in the number of hours of the month or year that a reduction can occur.

Demand response in practical terms is a temporary reduction in electricity usage in response to some external factor. That factor may be price or grid reliability, or some other element. Energy efficiency is a permanent, or near permanent, reduction in the electricity usage of a process with no appreciable drop in the quantity or quality of service level.

Figure 3 illustrates the connection between the electricity value chain and demand response strategies. The easiest $\mathrm{kWh}$ to save is typically the first, as firms begin by reducing their baseline usage, or "low hanging fruit." Other strategies become viable as further energy saving investments builds on the previous investment. For every firm the exact amount of electricity saved for a given period of time is different, however the extraction of the last few $\mathrm{kWh}$ will require strategies that can take advantage of fleeting opportunities. Moving from energy efficiency toward fast demand response is the logical progression for extracting all of the potential savings from the electricity value chain.

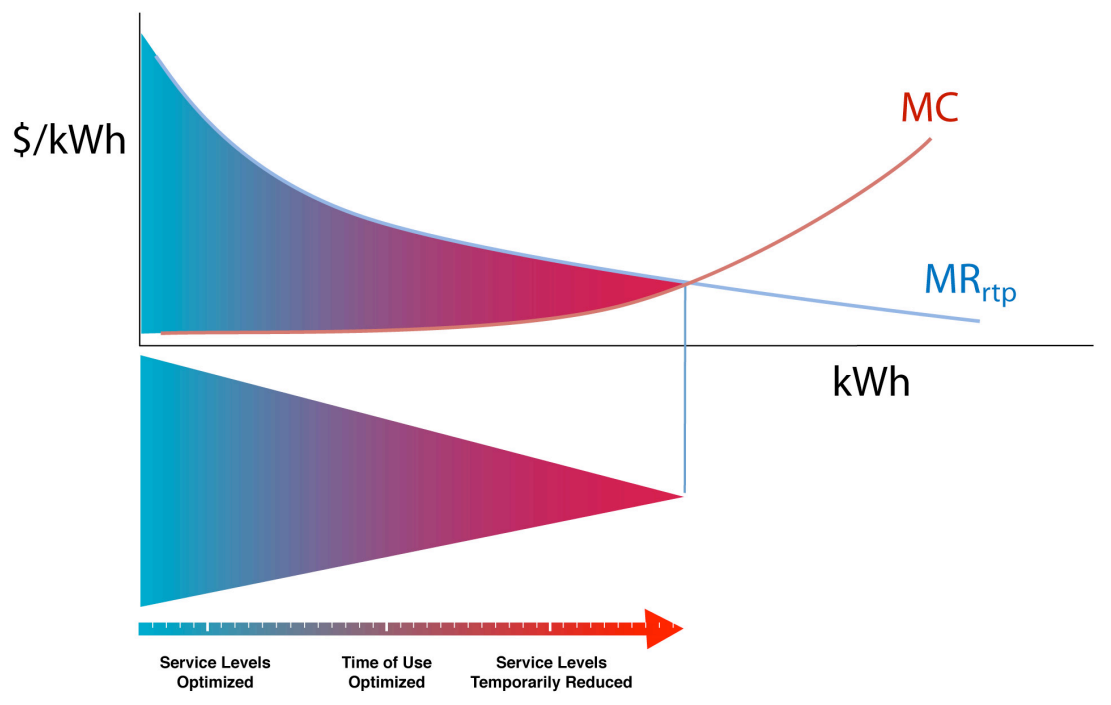

Figure 3: Maximizing Total Revenue Using DR

\section{Open Automated Demand Response (OpenADR) Research}

In 2006 the Public Interest Energy Research Program Demand Response Research Center (DRRC) at Lawrence Berkeley National Laboratory initiated research into Automated Demand Response (OpenADR) applications in industry. The DRRC formed an Industrial Demand Response Team to investigate opportunities and barriers to implementation of OpenADR systems in California industries. 
This research began with a review of previous OpenADR research on the commercial sector. Implementing OpenADR in industry presents a number of challenges, both practical and perceived. Some of these include: the variation in loads and processes across and within sectors, resource-dependent loading patterns that are driven by outside factors such as customer orders or time-critical processing (e.g. tomato canning), the perceived lack of control inherent in the term "automated", and aversion to risk -especially unscheduled downtime. While industry has demonstrated a willingness to temporarily provide large sheds and shifts to maintain grid reliability and be a good corporate citizen, the drivers for widespread OpenADR will likely differ. Ultimately, most industrial facilities will balance the real and perceived risks associated with participation against the potential for economic gain through favorable pricing or incentives. OpenADR, as with any ongoing industrial activity, will need to function effectively within market structures.

Developing a greater understanding of the opportunity for OpenADR is timely because the market for better controls and facility wide enterprise energy management is immature, but emerging rapidly. Early entries into this market have focused on load management, but these tools and strategies, if DR enabled, hold significant promise for integration into an OpenADR framework. Similarly, the emergence of higher quality system level network controls provide the missing link to allow improved management of key energy systems, and thus greater opportunities for DR and overall energy efficiency. The complete integration of load management, DR, and energy efficiency across an entire industrial plant may be within reach of many plants within the next decade. Under this scenario, even plants without onsite generation could, under pre-determined conditions, free up electricity to the grid to preserve the system reliability and manage the cost of delivering electricity while maintaining the economic health of their businesses.

OpenADR affords industrial facilities the opportunity to develop the supporting control structure and to "demo" potential reductions in energy use that can later be applied to more effective load management or a permanent reduction in use via energy efficiency.

\section{Research Goals and Methods}

The goals of the DRRC work on industrial OpenADR are to:

- Increase knowledge of what, where, for how long, and under what conditions industrial facilities will shed or shift load in response to an automated signal;

- Develop a better understanding of the dynamics of maximizing load reduction savings without affecting operations;

- Facilitate deployment of industrial OpenADR that is economically attractive and technologically feasible;

- More effectively target efforts to recruit industrial OpenADR sites, and

- Evaluate the opportunities to combine advanced controls and continuous measurement for optimal energy efficiency and DR. 
The DRRC seeks to achieve these goals by:

- Working with utilities and their contractors to identify OpenADR industrial participants;

- Providing technical assistance in evaluating Auto-DR sites;

- Collecting and analyzing data on DR recommendations included in utility integrated audits;

- Conducting in-depth analyses of industrial sectors that appear to have Auto-DR potential (refrigerated warehouses, wastewater facilities), and

- Analyzing industrial Auto-DR technical capacity and report on R\&D opportunities.

\section{Field Results}

In 2007 and 2008, 35 industrial facilities agreed to implement OpenADR, representing a total automated demand response capacity of nearly $40 \mathrm{MW}$. As illustrated in Table 1, more than half of the OpenADR capacity realized during this period resulted from large shifts in electricity use by the air separation industry. This industry is particularly well-suited for OpenADR for three reasons: sensitivity to electricity pricing due to level of use, fully automated controls, and the availability of substantial storage capacity. These storage capabilities have allowed some industrial gas facilities to reduce or postpone production for several hours without adverse effects on business operations.

In 2009 and ongoing, the DRRC Industrial Team is focusing on identifying smaller sheds and shifts in other industrial sectors, most notably refrigerated warehouses, wastewater facilities, and data centers. This paper will include a description of the research and case studies for two of these sectors, refrigerated warehouses and wastewater treatment facilities, to illustrate Auto-DR load reduction potential and typical shed and shift strategies.

\begin{tabular}{|c|c|c|}
\hline PG\&E 2007 & $\begin{array}{c}\text { Number } \\
\text { of } \\
\text { Service } \\
\text { Accounts }\end{array}$ & $\begin{array}{c}\text { Shed } \\
\text { Capability } \\
\text { (kW) }\end{array}$ \\
\hline Biotech & 3 & 172 \\
Biotech & 2 & 68 \\
Air Separation & 2 & 10,000 \\
Steel Recycling & 1 & 5,175 \\
Bakery & 1 & 100 \\
Manufacturing & 9 & 306 \\
\hline Total & $\mathbf{1 8}$ & $\mathbf{1 5 , 8 2 1}$ \\
\hline
\end{tabular}

Note: Open ADR participation is cumulative year to year

Open ADR commitments through 2008: $39.6 \mathrm{MW}$

\begin{tabular}{|c|c|c|}
\hline \multicolumn{3}{|l|}{ PG\&E 2008} \\
\hline Customer Type & $\begin{array}{c}\text { Number } \\
\text { of } \\
\text { Service } \\
\text { Accounts }\end{array}$ & $\begin{array}{c}\text { Shed } \\
\text { Capability } \\
\text { (kW) }\end{array}$ \\
\hline Air Separation & 1 & 1430 \\
\hline Biotech & 2 & 68 \\
\hline Refrigerated Warehouse & 3 & 550 \\
\hline Refrigerated Warehouse & 1 & 385 \\
\hline Total & 7 & 2,433 \\
\hline \multicolumn{3}{|l|}{ SCE 2008} \\
\hline Customer Type & $\begin{array}{l}\text { Number } \\
\text { of Sites }\end{array}$ & \begin{tabular}{|c|} 
Load \\
Shed \\
Capability
\end{tabular} \\
\hline Asphalt & $\overline{1}$ & 119 \\
\hline Aerospace manufacturing & 3 & 1315 \\
\hline Mobile Homes Manufacturing & 2 & 978 \\
\hline Air Separation & 1 & 13500 \\
\hline Asphalt/Rock Crushing & 1 & 1040 \\
\hline Battery production & 2 & 4400 \\
\hline Total & 10 & 21,352 \\
\hline
\end{tabular}

Table 1: 2007-2008 California Industrial OpenADR Implementation Sites ${ }^{3}$ 
The Industrial DRRC research on OpenADR opportunities in industrial refrigerated warehouses and wastewater treatment facilities is primarily characterized by extensive literature research on end-use process loads, control capabilities and the state of OpenADR readiness, and case studies on successful energy efficiency, load management, and demand response measures, enhanced by initial field studies. The current research results show that the technologies that enhance energy efficiency and control within industrial facilities also enable these facilities to become successful demand response participants. Comprehensive and real-time demand control from centralized computer control systems allows facility managers to coordinate and schedule load shedding and shifting through equipment-level controls to reduce energy demand during utility peak hours. The following describes several load shedding and load shifting opportunities for industrial refrigerated warehouses and wastewater treatment facilities.

\section{Refrigerated Warehouses OpenADR Opportunities}

Load Shifting: Load shifting changes the time of electricity demand to off-peak hours. Load shifting strategies for an industrial refrigerated warehouse can include cold storage space pre-cooling, shifting battery charger loads, and disabling electric defrost during demand response events. Pre-cooling reduces refrigerated warehouse space temperatures below predefined temperature set-points before a demand response event, allowing refrigeration equipment to be turned off during an event without impacting product quality. The ability to successfully pre-cool depends on the thermal mass of the product as well as the mass and temperature of any products leaving or being introduced into the storage area. Recharging batteries can also be scheduled so that battery chargers can be shut-down during demand response events. Further, automatic evaporator electric defrosting can be disabled during a demand response event to reduce loads.

Load Shedding: Load shedding curtails electricity demand during a DR event. Load shedding strategies for an industrial refrigerated warehouse can include turning off equipment, increasing cold storage area temperature set points, reducing lighting and HVAC loads, and utilizing multi-stage or VFD controls to run equipment at lower capacity. Refrigerated warehouse loads can be reduced by turning off, or reducing the operating capacity of equipment such as compressors and condenser and evaporator fans off during DR events. Another potential shed strategy involves increasing the temperature set point in refrigeration units, which, in turn, reduces compressor loads. As in the case of turning off equipment, the magnitude of the set-point change depends on product sensitivity, and the level of shell insulation in the refrigerated warehouse. Lighting as well as heating, ventilation, and air-conditioning (HVAC) loads in non-essential areas can be shed by turning off or dimming groups of lighting, and turning off HVAC equipment and increasing temperature set-points in office spaces. The lighting demand reduction also results in less heat released in the cold storage space, thus lowering the cooling loads.

Figure 4 shows the results of demand reduction in an industrial refrigerated warehouse. The load reduction was accomplished primarily by increasing temperature set-points in cold storage areas. The chart on the left of Figure 4 shows the demand reduction's effect on the whole facility load during the peak demand period, while the 
chart on the right of Figure 4 shows the demand reduction compared only to the cold storage load.

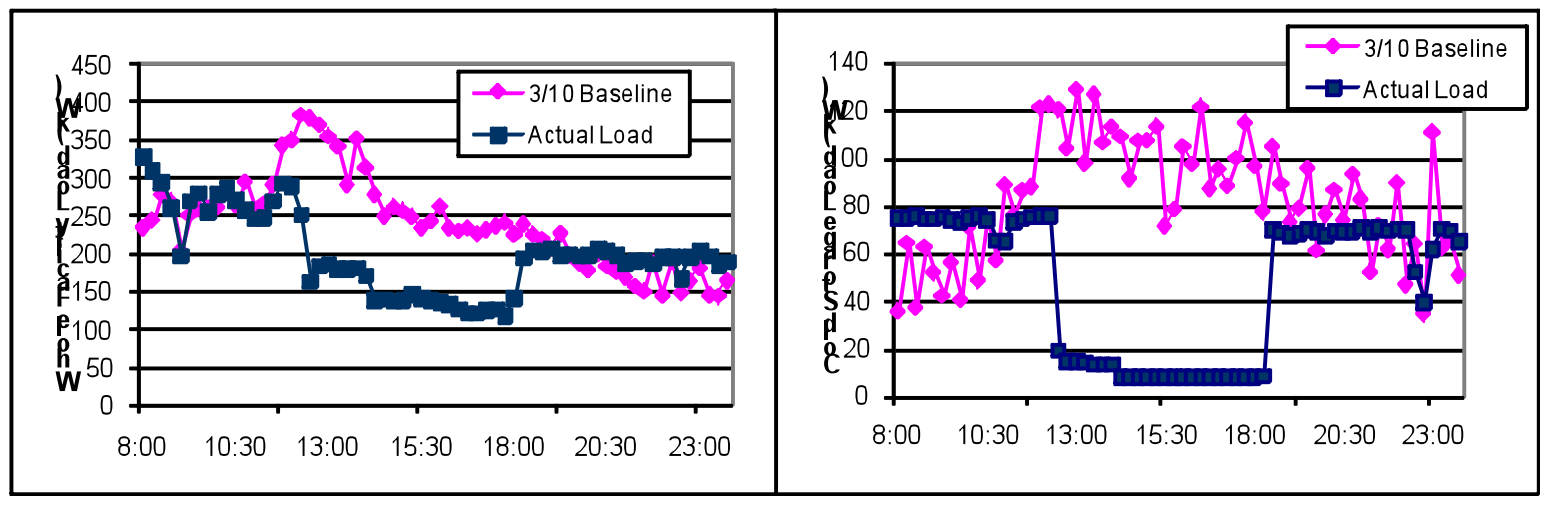

Figure 4: Demand Reduction in Refrigerated Warehouse

Case Studies: There are a number of examples of facilities which have successfully implemented load management and DR measures. The DRRC 2009 report on industrial refrigerated warehouses describes several case studies ranging from a 60,000 square foot winery to a 450,000 square foot refrigerated warehouse facility. ${ }^{8}$ These sites participated in DR measures such as turning off refrigeration equipment and lighting and HVAC systems. In one of the facilities, the set of DR measures resulted in demand savings of over $200 \mathrm{~kW}$. Some of the case studies also describe implementation of energy efficiency measures such as installing more efficient equipment and increasing envelope insulation. The set of energy efficiency measures in one facility resulted in annual energy savings of over 1.8 million $\mathrm{kWh}$.

A case study from one of the refrigerated warehouses participating in the PG\&E service territory, U.S. Foodservice, provides an example of successful implementation of OpenADR. The U.S. Foodservice distribution warehouse in Livermore, California stores more than 10,000 products and includes a 345,000 square foot freezer, which maintains temperatures between $-1^{\circ}$ to $1^{\circ} \mathrm{F} .{ }^{10}$ The facility electrical load ranges from $700-900 \mathrm{~kW}$, with the freezer accounting for 30 to 40 percent of the total load.

The facility was an excellent candidate for OpenADR participation due to the freezer and HVAC system's stable electrical load. Additionally, the site already had installed the controls and communication structure necessary to implement OpenADR. The facility conducted several test DR events in the spring of 2008, in which the refrigeration units serving the freezer were turned off, the temperature set-point of the HVAC system was raised, and battery charger banks were turned off. These strategies enabled the facility to shed about 25 percent of its total load, with a maximum load reduction of $330 \mathrm{~kW}$. Turning off the compressors and the air handlers serving the freezer achieved the largest demand reduction. After a six-hour test event, the air temperature in the cold storage area rose between $1.2^{\circ} \mathrm{F}$ and $8.6^{\circ} \mathrm{F}$, without impacting facility operations and product quality. 


\section{Wastewater Treatment Facilities OpenADR Opportunities}

Load Shedding: Opportunities for load shedding during DR events for wastewater facilities include turning non-essential equipment off and transitioning essential equipment to onsite power generators. Facilities can turn off aerator blowers, filling and backwash filter pumps, facility HVAC systems, and other non-essential equipment to shed electrical load during peak hours. Alternatively, facilities can use multi-stage or variable frequency drives (VFD) controls to operate this equipment at lower capacity that reduces demand and better matches the requirements for operation within regulatory limits. Centralized control systems can provide wastewater treatment facilities with capability to automatically switch to running onsite power generators during peak demand periods. ${ }^{4}$ Onsite power generators running on anaerobic digester gas, a byproduct of the treatment process, can provide off-grid power during demand response events. This strategy has been proven successful in municipal wastewater treatment facilities. For example, the East Bay Municipal Utilities District has implemented a load management strategy which includes storing anaerobic digester gas until it can be used during peak-demand periods. ${ }^{5}$

Load Shifting: Implementing load shifting strategies in wastewater treatment facilities can allow the main energy-intensive treatment processes to be rescheduled to off-peak hours. ${ }^{6}$ A major opportunity for shifting wastewater treatment loads from peak demand hours to off-peak hours is over-oxygenating stored wastewater prior to a demand response event. This allows aerators to be turned off during the peak period. However, facilities must be careful to monitor and maintain the correct range of aeration since excessive oxygenation due to prolonged detention time can also adversely affect effluent quality. Further, wastewater treatment facilities can also utilize available excess storage capacity to store untreated wastewater during demand response events and process it during off-peak hours. ${ }^{5}$ Additionally, facility processes such as backwash pumps, biosolids thickening, dewatering and anaerobic digestion can be rescheduled for operation during off-peak periods. 4

Case Studies: There are a number of examples of wastewater treatment facilities which have successfully implemented load management and demand response measures. The DRRC 2009 study on wastewater treatment facilities describes energy efficiency and load management measures such as replacing aerators with solar-power mixers, installing automatic dissolved oxygen sensors, and rescheduling treatment processes to off-peak hours. ${ }^{9}$ These measures saved one facility 60 percent of its energy use and reduced demand in another facility by $79 \mathrm{~kW}$. Field work in OpenADR in wastewater treatment will commence during the 2009 summer period, however, a case study of the Encina Wastewater Authority provides an example of a municipal wastewater treatment facility which has implemented several successful energy efficiency and load management measures, thus preparing the facility to progress through the electricity value chain to OpenADR.

The Encina Wastewater Authority serves North San Diego county and processes 36 million gallons of water per day. ${ }^{11}$ During the last several years, Encina implemented several energy efficiency strategies and load management measures. Energy efficiency measures included upgrading coarse-bubble diffusers with fine-bubble design and introducing probes throughout aeration basins to monitor and maintain dissolved oxygen 
levels automatically. Load management efforts included rescheduling pumping and treatment processes to off-peak hours and manually shutting down energy intensive equipment during peak hours. The implementation of these strategies saves the Encina Wastewater Authority over $\$ 600,000$ each year, with the load management efforts alone savings $\$ 50,000$ annually.

\section{Conclusions}

Initial research conducted by the DRRC in California industry indicates that if the transaction is properly valued and part of a carefully tested agreement between the facility and the electricity supplier, OpenADR in industry offers significant potential to improve electric grid reliability and lower electricity use during periods of peak demand. The electricity value chain provides a conceptual framework for understanding the relationships between energy efficiency, load management, and demand response (both day ahead - manual or real time- automated). Profit maximization occurs where the marginal cost of saving a kilowatt-hour $(\mathrm{kWh})$ of electricity just equals the marginal revenue generated by the savings. By targeting industrial sectors that appear to have promise, the DRRC seeks to continue to add to the body of knowledge concerning the valuation trade-offs between production and specific OpenADR shift and shed strategies.

Future research will focus on developing a better understanding of the current state of the controls infrastructure in a number of additional industrial sectors, thus identifying sectors with the capacity to participate in OpenADR with a minimal level of capital investment.

\section{Acknowledgements}

This work was sponsored by the Demand Response Research Center which is funded by the California Energy Commission (Energy Commission), Public Interest Energy Research (PIER) Program, under Work for Others Contract No.150-99-003, Am \#1 and by the U.S. Department of Energy under Contract No. DEAC03-76SF00098. Special acknowledgements to Michael Gravely and Pramod Kulkarni for there support of this research

\section{References}

1. McKane, A. T., Mary Ann Piette, David Faulkner, Girish Ghatikar, Anthony

Radspieler Jr., Bunmi Adesola, Scott Murtishaw and Sila Kiliccote, Opportunities, Barriers and Actions for Industrial Demand Response in California, 2009. Lawrence Berkeley National Laboratory. Report No. LBNL1335E.

2. Piette, M. A., Sila Kiliccote, and Girish Ghatikar, Linking Continuous Energy Management and Open Automated Demand Response. In Grid Interop Forum. 2008. Atlanta, GA. Lawrence Berkeley National Laboratory.

3. Demand Response Research Center, Demand Response Research Center PIER Team Briefing, 2008. Lawrence Berkeley National Laboratory. Berkeley. 
4. Carns, K., Quality Energy Efficiency Retrofits for Wastewater Systems, 1998. EPRI. Report No. CR-109081.

5. Environmental Protection Agency, Wastewater Management Fact Sheet Energy Conservation Office of Water, Editor. 2006.

http://www.p2pays.org/energy/WastePlant.pdf

6. ITT Corporation, ITT's Place in the Cycle of Water.

$<$ http://www.ittfluidbusiness.com/media/ITT WTRBK v6 download.pdf $>$

7. Electric Power Research Institute, Energy Audit Manual for Water/Wastewater Facilities. 1994

8. Demand Response Research Center, Opportunities for Energy Efficiency and Automated Demand Response in Industrial Refrigerated Warehouses - Draft Report, 2009. Lawrence Berkeley National Laboratory. Berkeley.

9. Demand Response Research Center, Opportunities for Energy Efficiency and Automated Demand Response in Wastewater Treatment Facilities - Draft Report, 2009. Lawrence Berkeley National Laboratory. Berkeley.

10. Demand Response Research Center, Refrigerated Warehosue Participates in Open Auto-DR, Saving Energy, and Receiving Incentives, 2009. Lawrence Berkeley National Laboratory. Berkeley.

11. California Energy Commission, Water/Wastewater Process Energy, Case Studies: Encina Wastewater Authority, 2003. 